\title{
Hepatitis $C$ drugs: The end of the pegylated interferon era and the emergence of all-oral, interferon-free antiviral regimens: A concise review
}

\author{
Alan Hoi Lun Yau MD, Eric M Yoshida MD MHSc FRCPC
}

AHL Yau, EM Yoshida. Hepatitis C drugs: The end of the pegylated interferon era and the emergence of all-oral, interferonfree antiviral regimens: A concise review. Can J Gastroenterol Hepatol 2014;28(8):445-451.

Between 2001 and 2011, the standard of care for chronic hepatitis C virus $(\mathrm{HCV})$ infection was a combination of pegylated interferon (PEGIFN) and ribavirin (RBV). In May 2011, boceprevir and telaprevir, two first-generation NS3/4A protease inhibitors, were approved in combination with PEG-IFN and RBV for 24 to 48 weeks in hepatitis $C$ virus genotype 1 infections. In December 2013, simeprevir, a second-generation NS3/4A protease inhibitor, was approved for use with PEG-IFN and RBV for 12 weeks in genotype 1, while sofosbuvir, a NS5B nucleotide polymerase inhibitor, was approved for use with PEG-IFN and RBV for 12 weeks in genotypes 1 and 4, as well as with RBV alone for 12 weeks in genotype 2 and for 24 weeks in genotype 3. Sofosbuvir combined with simeprevir or an NS5A replication complex inhibitor (ledipasvir or daclatasvir) with or without RBV for 12 weeks in genotype 1 resulted in a sustained virological response $>90 \%$, irrespective of previous treatment history or presence of cirrhosis. Similarly impressive sustained virological response rates have been shown with ABT-450/r (ritonavir-boosted NS3/4A protease inhibitor)-based regimens in combination with other direct-acting antiviral agent(s) with or without RBV for 12 weeks in genotype 1 . The optimal all-oral interferon-free antiviral regimen likely entails a combination of an NS5B nucleotide polymerase inhibitor with either a second-generation NS3/4A protease inhibitor or an NS5A replication complex inhibitor with or without RBV. Further research is needed to determine the role of resistance testing, clarify the optimal follow-up duration posttreatment, and evaluate the antiviral efficacy and safety in difficultto-cure patient populations.

Key Words: All-oral; Hepatitis C; Interferon-free; Simeprevir; Sofosbuvir

\author{
Les médicaments contre l'hépatite $\mathrm{C}:$ la fin de l'ère \\ de l'interféron pégylé et l'émergence d'une \\ posologie antivirale entièrement orale et sans \\ interféron : une analyse concise
}

Entre 2001 et 2011, la norme des soins de l'infection par le virus de l'hépatite $\mathrm{C}(\mathrm{VHC})$ chronique était une polythérapie d'interféron pégylé (IFN-PEG) et de ribavirine (RBV). En mai 2011, le bocéprévir et le télaprévir, deux inhibiteurs de la protéase NS3/4A de première génération, ont été approuvés en combinaison avec l'IFN-PEG et la RBV pour un traitement de 24 à 48 semaines contre l'infection par le VHC de génotype 1. En décembre 2013, le siméprévir, un inhibiteur de la protéase NS3/4A de seconde génération, a été approuvé en combinaison avec l'IFN-PEG et la RBV pour un traitement de 12 semaines contre le génotype 1 , tandis que le sofosbuvir, un inhibiteur nucléotidique de la polymérase NS5B, a été approuvé en combinaison avec l'IFN-PEG et la RBV pour un traitement de 12 semaines contre les génotypes 1 et 4 , ainsi qu'avec la RBV seule pour un traitement de 12 semaines contre le génotype 2 et de 24 semaines contre le génotype 3 . Le sofosbuvir en combinaison avec le siméprévir ou un inhibiteur du complexe de réplication NS5A (lédipasvir ou daclatasvir), accompagné ou non de RBV et administré pendant 12 semaines pour traiter le génotype 1 , a suscité une réponse virologique soutenue de plus de $90 \%$, quels que soient les antécédents thérapeutiques et en présence ou en l'absence de cirrhose. De même, les posologies à base d'ABT-450/r (inhibiteur de la protéase NS3/4A rehaussé de ritonavir), combinées à d'autres antiviraux à action directe avec ou sans RBV pour un traitement de 12 semaines contre le génotype 1, entrânent un taux de réponse virologique soutenu impressionnant. La posologie antivirale entièrement orale et sans interféron optimale se compose probablement d'un inhibiteur nucléotidique de la polymérase NS5B combiné à un inhibiteur de la protéase NS3/4A de seconde génération ou à un inhibiteur du complexe de réplication NS5A, accompagné ou non de RBV. Il faudra mener d'autres recherches pour déterminer le rôle des tests de résistance, établir la durée de suivi optimale après le traitement et évaluer l'efficacité et l'innocuité antivirale au sein des populations de patients difficiles à soigner.

\footnotetext{
$\mathrm{C}$ hronic hepatitis $\mathrm{C}$ virus (HCV) infection has been estimated to affect $2 \%$ to $3 \%$ (170 million individuals) of the population worldwide (1) and 0.8\% (275,000 individuals) of Canadians (2). In Canada, HCV-related morbidity and mortality increased by $15 \%$ to $18 \%$ annually between 1994 and 2004 (3). In response to the increasing medical and economic burden of HCV on the Canadian health care system, the landscape of HCV antiviral therapy has changed rapidly in the past three years (Table 1) (4). Between 2001 and 2011, the standard of care for chronic HCV infection was a combination of pegylated interferon (PEG-IFN) and ribavirin (RBV), with a sustained virological response (SVR) of up to $40 \%$ to $50 \%$ in genotype 1 (G1) and up to $70 \%$ to $80 \%$ in genotypes 2 and $3(G 2 / 3)(5,6)$. However, PEG-IFN is contraindicated in decompensated cirrhosis (7) and is associated with constitutional, neuropsychiatric, autoimmune and hematological side effects (8), whereas RBV is contraindicated in renal failure (9) and is associated with cough, rash, hemolysis and teratogenesis (8). Hence, many patients are ineligible for or intolerant to PEG-IFN and RBV therapy.
}

\section{DIRECT-ACTING ANTIVIRAL AGENTS IN COMBINATION WITH PEG-IFN AND RBV: \\ WHAT IS CURRENTLY AVAILABLE}

The limited efficacy and tolerability of PEG-IFN and RBV have prompted the development of many direct-acting antiviral agents (DAAs) that target specific proteins involved in HCV replication (Table 2) (10). In May 2011, boceprevir (BOC) and telaprevir (TVR), two first-generation NS3/4A protease inhibitors, were approved for use in HCV G1, but must be used in combination with PEG-IFN and RBV to prevent the rapid emergence of resistance-associated variants (11-13). Although BOC and TVR have significantly improved the SVR to $60 \%$ to $75 \%$ in G1 treatment-naive patients (11-13), the SVR remained suboptimal (30\% to $40 \%$ ) in difficult-to-cure populations such as patients with cirrhosis (14), Gla (15), and previous null responders to PEG-IFN and RBV (defined as failure to achieve at least a $2 \mathrm{log}$ reduction in HCV RNA at week 12 of therapy) (16,17). Moreover, protease inhibitors are associated with additional side effects including

Department of Medicine, Division of Gastroenterology, University of British Columbia, Vancouver, British Columbia

Correspondence: Dr Eric Yoshida, Vancouver General Hospital, Division of Gastroenterology, 5153-2775 Laurel Street, Vancouver,

British Columbia V5Z 1M9. Telephone 604-875-5371, fax 604-875-5447, e-mail eric.yoshida@vch.ca

Received for publication April 6, 2014. Accepted June 16, 2014 
TABLE 1

Currently approved hepatitis $\mathrm{C}$ treatment regimens

\begin{tabular}{llcll}
\hline Year & Treatment regimen & Genotype & SVR, \% & Study (reference) \\
\hline 2001 & PEG-IFN + RBV $\times 48$ weeks & 1 or 4 & $42-46$ & Manns et al (5), Fried et al (6) \\
2001 & PEG-IFN + RBV $\times 24$ weeks & 2 or 3 & $76-82$ & Manns et al (5), Fried et al (6) \\
2011 & PEG-IFN + RBV + BOC $\times 24-48$ weeks & 1 & $56-75$ & SPRINT-1 (11), SPRINT-2 (12) \\
2011 & PEG-IFN + RBV + TVR $\times 24-48$ weeks & 1 & $69-75$ & ADVANCE (13) \\
2013 & PEG-IFN + RBV + SMV $\times 12$ weeks & 1 & $80-81$ & QUEST-1 (19), QUEST-2 (20), PILLAR (21) \\
2013 & PEG-IFN + RBV + SOF $\times 12$ weeks & 1 & $89-91$ & NCT01188772 (25), ATOMIC (26), NEUTRINO (27) \\
2013 & PEG-IFN + RBV + SOF $\times 12$ weeks & 4 & 96 & NEUTRINO (27) \\
2013 & RBV + SOF $\times 12$ weeks & 2 & $92-100$ & FISSION (27), POSITRON (35), VALENCE (36) \\
2013 & RBV + SOF $\times 24$ weeks & 3 & $92-94$ & VALENCE (36) \\
\hline
\end{tabular}

${ }^{*}$ Followed by pegylated interferon (PEG-IFN) + ribavirin (RBV) for 12 weeks in treatment-naive or previous relapsers and 36 weeks in previous partial or null responders. Sofosbuvir (SOF) + RBV is recommended in hepatocellular carcinoma patients awaiting liver transplantation for up to 48 weeks or until transplant. BOC Boceprevir; SMV Simeprevir; SVR Sustained virological response in treatment-naive patients; TVR Telaprevir

\section{TABLE 2}

General characteristics of direct-acting antiviral agents

\begin{tabular}{|c|c|c|c|c|c|}
\hline Direct-acting antiviral agents & Antiviral efficacy & Resistance barrier & Genotypic coverage & Side effects & Drug interactions \\
\hline NS3/4A protease inhibitor (first generation) & ++ & + & Genotype 1 & +++ & +++ \\
\hline NS3/4A protease inhibitor (second generation) & +++ & ++ & Multiple genotypes & + & ++ \\
\hline NS5A replication complex inhibitor & +++ & ++ & Multiple genotypes & + & ++ \\
\hline NS5B nucleotide polymerase inhibitor & +++ & +++ & All genotypes & + & + \\
\hline NS5B non-nucleoside polymerase inhibitor & ++ & + & Genotype 1 & ++ & ++ \\
\hline
\end{tabular}

+ Minimal; ++ Intermediate; +++ Significant; NS Nonstructural protein

anemia and dysgeusia for BOC and anemia, and rash and anorectal symptoms for TVR (18). Finally, the use of triple therapy is associated with a heavy pill burden, complex dosing schedule and numerous drug interactions, even though the treatment duration could be shortened from 48 weeks to 24 to 28 weeks through response-guided therapy.

Following the approval of BOC and TVR, second-generation NS3/4A protease inhibitors, such as simeprevir (SMV), were being developed. In December 2013, SMV was approved for use with PEGIFN and RBV for 12 weeks in G1. The approval was based on data from the QUEST-1 (19), QUEST-2 (20) and PILLAR (21) clinical trials in which SMV in combination with PEG-IFN and RBV for 12 weeks followed by PEG-IFN and RBV alone for an additional 12 to 36 weeks produced an SVR of $80 \%$ to $81 \%$ in G1 treatment-naive patients. A similar SVR (79\%) was shown with the same treatment regimen in G1 previous relapsers to PEG-IFN and RBV in the PROMISE study (22). This was further confirmed in the ASPIRE study, in which 12 weeks of SMV given with 48 weeks of PEG-IFN and RBV resulted in an SVR of $77 \%$ in previous relapsers; however, a lower SVR of $65 \%$ and $53 \%$ was found in previous partial and null responders, respectively (23). In all of these studies (19-23), the SVR in G1a was significantly lower ( $58 \%$ if Q80K positive, $75 \%$ if Q80K negative) than in G1b (>80\%) due to the presence of the $\mathrm{Q} 80 \mathrm{~K}$ polymorphism, which is commonly found in $30 \%$ to $47 \%$ of Gla infections and significantly decreases susceptibility to SMV (24). This has strong clinical implications in North America, where G1a is the most prevalent HCV subgenotype and where Q80K polymorphism testing is recommended in G1a patients before treatment with SMV.

Because first- and second-generation protease inhibitors may develop cross-resistance, other classes of DAA, such as nucleotide NS5B polymerase inhibitors, which include sofosbuvir (SOF), were being developed. In December 2013, SOF was approved for use with PEG-IFN and RBV for 12 weeks in G1 and G4 infections. The approval was based on data from the NCT01188772 (25), ATOMIC (26) and NEUTRINO (27) clinical trials in which SOF in combination with PEG-IFN and RBV for 12 weeks produced an SVR of $89 \%$ to $91 \%$ in G1 treatment-naive patients. The NEUTRINO study also reported an SVR of $96 \%$ in G4 treatment-naive patients who received PEG-IFN, RBV and SOF for 12 weeks. G1a was present in $69 \%$ to
$77 \%$ among these studies and cirrhosis was identified as a negative predictor of SVR ( $80 \%$ with cirrhosis, $92 \%$ without cirrhosis) in the NEUTRINO study. G2 and G3 treatment-naive patients also appear to benefit from the same treatment regimen, with an SVR of $92 \%$ to 96\% in the NCT01188772 (25) and PROTON (28) studies. A similar SVR (83\% to $96 \%$ ) was demonstrated with this regimen in G2 and G3 treatment-experienced patients, in whom compensated cirrhosis was present in $50 \%$ of enrolled patients in the LONESTAR-2 study (29).

The addition of a DAA to the backbone of PEG-IFN and RBV has clearly improved the likelihood of achieving an SVR; however, SOF appears to be superior to BOC, TVR and SMV in enhancing antiviral efficacy. The first-generation protease inhibitors BOC and TVR are associated with significant adverse effects, which are in addition to those of PEG-IFN and RBV. The commercial availability of SMV and SOF offers patients a shortened treatment course and a lack of adverse effects experienced with BOC and TVR. The continued use of PEGIFN and RBV in these new antiviral combinations, however, remains problematic because patients with decompensated cirrhosis and significant medical and/or psychiatric comorbidities are excluded from treatment. Moreover, the need for intensive monitoring of patients on PEG-IFN- and RBV-containing regimens imposes a heavy clinical burden on nursing care in chronic HCV.

\section{DAAs WITHOUT PEG-IFN: EARLY CLINICAL TRIALS AND WHAT IS CURRENTLY AVAILABLE}

The limited safety and tolerability of interferon (IFN)-based regimens (Table 3) have led to the development of IFN-free regimens that have been shown to have a superior impact on health-related quality of life and cost effectiveness (30-32). In 2010, Gane et al (33) published the first proof-of-concept study (INFORM-1) that demonstrated that potent viral suppression could be achieved with IFN-free DAA combination therapy whereby danoprevir (NS3/4A protease inhibitor) and mericitabine (NS5B nucleotide polymerase inhibitor) in combination for two weeks produced a $4.9 \mathrm{IU} / \mathrm{mL}$ and $5.1 \log _{10} \mathrm{IU} / \mathrm{mL}$ decrease in HCV RNA in G1 treatment-naive and previous null responder patients, respectively. In 2012, Lok et al (34) published the first curative-intent study that showed that an SVR could be achieved with an IFN-free regimen whereby asunaprevir (NS3/4A protease 
TABLE 3

Common adverse events of simeprevir (SMV)- and sofosbuvir (SOF)-based regimens

\begin{tabular}{|c|c|}
\hline Treatment regimen & Adverse events \\
\hline PEG-IFN + RBV + SMV & Anemia, fatigue, headache, hyperbilirubinemia, influenza-like illness, neutropenia, photosensitivity, pruritus, rash \\
\hline PEG-IFN + RBV + SOF & Anemia, fatigue, headache, influenza-like illness, insomnia, nausea, neutropenia, rash, thrombocytopenia \\
\hline $\mathrm{RBV}+\mathrm{SOF}$ & Anemia, diarrhea, fatigue, headache, insomnia, nausea, pruritus, rash \\
\hline
\end{tabular}

PEG-IFN Pegylated interferon; RBV Ribavirin

inhibitor) and daclatasvir (NS5A complication complex inhibitor) given for 24 weeks to G1 previous null responders produced an SVR of $36 \%$, which was interesting given the presence of G1a HCV subgenotype in $82 \%$ and non-CC IL28B genotype in $91 \%$.

Subsequent clinical trials involving IFN-free regimens have shown more promising efficacy (Table 4). In December 2013, SOF was approved for use with RBV for 12 weeks in G2 and for 24 weeks in G3 based on results from the following studies. In G2 treatment-naive patients, SOF and RBV for 12 weeks produced an SVR of $92 \%$ to $97 \%$ in noncirrhotics and 94 to $100 \%$ in cirrhotics in the FISSION (27), POSITRON (35) and VALENCE (36) clinical trials. In G2 treatment-experienced patients, SOF and RBV for 12 weeks resulted in a SVR of $91 \%$ to $96 \%$ in noncirrhotics and $60 \%$ to $88 \%$ in cirrhotics in FUSION (35) and VALENCE (36). In G3 treatment-naive patients, SOF and RBV for 12 weeks produced a SVR of $68 \%$ in noncirrhotics and $21 \%$ to $56 \%$ in cirrhotics in FISSION (27) and POSITRON (35); however, extending the duration of SOF and RBV to 24 weeks improved the SVR to $94 \%$ in noncirrhotics and $92 \%$ in cirrhotics in VALENCE (36). In G3 treatment-experienced patients, SOF and RBV for 12 to 16 weeks resulted in an SVR of 37\% to $63 \%$ in noncirrhotics and $19 \%$ to $61 \%$ in cirrhotics in FUSION (35). Extending the duration of SOF and RBV to 24 weeks improved the SVR to $87 \%$ in noncirrhotics but the SVR remained suboptimal (60\%) in cirrhotics in VALENCE (36). However, the SVR did improve to $83 \%$ in G3 treatment-experienced cirrhotics when PEG-IFN was added to SOF and RBV for 12 weeks in LONESTAR-2 (29). In summary, an excellent SVR was demonstrated with SOF and RBV for 12 weeks in G2 and for 24 weeks in G3 irrespective of previous treatment history or presence of cirrhosis, with the exception of G3 treatment-experienced cirrhotics who required the addition of PEG-IFN to SOF and RBV for 12 weeks.

The use of SOF and RBV for 24 weeks could also be considered in G1 patients who are ineligible for PEG-IFN, although the efficacy appears to be more limited (Table 4). In G1 treatment-naive patients, SOF and RBV for 12 weeks produced an SVR of $84 \%$ in noncirrhotics in ELECTRON (37), but only 56\% in a patient population consisting of $4 \%$ to $8 \%$ cirrhotics in QUANTUM (38). Extending the duration of SOF and RBV to 24 weeks in QUANTUM did not improve the SVR which remained suboptimal at 52\% (38). However, combination DAA with SMV and SOF with or without RBV for 12 weeks produced a SVR of $67 \%$ to $100 \%$ in G1 treatment-naive cirrhotics in COSMOS (39-41). In G1 previous null responders, SOF and RBV for 12 weeks resulted in a disappointing SVR of $10 \%$ in noncirrhotics in ELECTRON (37). However, combination DAAs with SMV and SOF with or without RBV for 12 weeks in G1 previous null responders produced an impressive SVR of $93 \%$ to $96 \%$ in noncirrhotics and $80 \%$ to $100 \%$ in cirrhotics in COSMOS (39-41). In summary, a modest SVR was demonstrated with SOF and RBV for 12 weeks in G1 treatmentnaive noncirrhotics, whereas a combination os DAAs with SMV and SOF with or without RBV for 12 weeks was required for G1 treatmentnaive cirrhotics and G1 prior null responders with or without cirrhosis. It appears that the addition of RBV may not be needed to achieve a SVR when two potent DAAs are used in combination, as shown in COSMOS (39-41); however, RBV appears to be necessary when a single DAA is used as shown in ELECTRON (37), in which SOF with and without RBV for 12 weeks produced an SVR of $100 \%$ and $60 \%$, respectively, in G2/3 treatment-naive noncirrhotics. It has been postulated that RBV may accelerate viral clearance and, thereby, suppress the emergence of DAA resistance (42).

\section{DAAs WITHOUT PEG-IFN: RECENT CLINICAL TRIALS AND WHAT MAY BE AVAILABLE IN THE FUTURE}

Following the success of SMV and SOF in COSMOS (39), several other SOF-based regimens in combination with another DAA have also shown impressive results (Table 4). In G1 treatment-naive noncirrhotic patients, SVR with ledipasvir (LDV) (NS5A replication complex inhibitor) and SOF with or without RBV for eight weeks was $93 \%$ to $100 \%$ in ION-3 (43) and LONESTAR (44); daclatasvir (DCV) (NS5A replication complex inhibitor) and SOF with or without RBV for 12 weeks was $95 \%$ to $100 \%$ in AI444040 (45); and GS-9669 (NS5B non-nucleoside polymerase inhibitor) and SOF with RBV for 12 weeks was $92 \%$ in ELECTRON (46). In G1 treatmentnaive patients in whom cirrhosis was present in $16 \%$, LDV and SOF with or without RBV for 12 weeks resulted in a SVR of $97 \%$ to $99 \%$ in ION-1 (47). In G1 previous null-responders to PEG-IFN and RBV, an SVR of $100 \%$ was produced with GS-9669, SOF, and RBV for 12 weeks in noncirrhotic patients and with LDV, SOF and RBV for 12 weeks in noncirrhotics and cirrhotics in ELECTRON (46). In G1 patients with previous virological failure to protease inhibitor-based regimens (ie, BOC or TVR), DCV and SOF with or without RBV for 24 weeks produced a SVR of 95 to $100 \%$ in noncirrhotics in AI444040 (45), whereas LDV and SOF with or without RBV for 12 weeks resulted in a SVR of $94 \%$ to $100 \%$ in a patient population consisting of cirrhosis in $20 \%$ in ION-2 (48) and in 55\% in LONESTAR (44). Importantly, these findings demonstrated that failing the protease inhibitor class of DAAs does not preclude treatment success with another class. Finally, the AI444040 (45) study showed that DCV and SOF with or without RBV for 24 weeks produced a SVR of $92 \%$ in G2 and $89 \%$ in G3 treatment-naive noncirrhotic patients. In summary, an impressive SVR $>90 \%$ was demonstrated in G1 with SOF in combination with LDV or DCV or GS-9669 with or without RBV for 12 weeks irrespective of treatment history or the presence of cirrhosis. Furthermore, the majority of patients in these studies had unfavourable characteristics including G1a HCV subgenotype and non-CC IL-28B genotype, which strongly suggest that their relevance in IFN-free regimens is minor.

Aside from SOF, another NS5B nucleotide polymerase inhibitor, mericitabine (MCB), was also evaluated in clinical trials although results were less encouraging. In G1 treatment-naive noncirrhotic patients, MCB in combination with ritonavir-boosted danoprevir (NS3/4A protease inhibitor) and RBV for 24 weeks produced a SVR of only $41 \%$ which was significantly lower in G1a at $26 \%$ compared with G1b (71\%) in INFORM-SVR (49). In G1b treatmentexperienced noncirrhotics, the same treatment regimen resulted in a SVR of $39 \%$ in previous partial responders and $55 \%$ in previous null responders in MATTERHORN (50). Based on these disappointing results, $\mathrm{MCB}$ is unlikely to be selected as an optimal candidate in DAA combination therapy.

High rates of SVR have also been shown without using NS5B nucleotide polymerase inhibitors as backbone in ABT-450/r (ritonavir-boosted NS3/4A protease inhibitor) -based regimens (Table 4). In G1 treatmentnaive noncirrhotic patients, ABT-450/r in combination with ombitasvir (ABT-267) (NS5A replication complex inhibitor) for 12 weeks produced a SVR of $95 \%$ in G1b in PEARL-I (51) but only $60 \%$ in M12-998 (52) in which G1a was present in $80 \%$ of enrolled patients. The decrease in SVR in G1a was also observed in previous clinical trials with protease inhibitor-based regimens. However, the SVR improved to $100 \%$ with the addition of RBV in M12-998 (52) and to 
TABLE 4

Sustained virological response (SVR) of sofosbuvir (SOF)- and ABT-450/r-based regimens

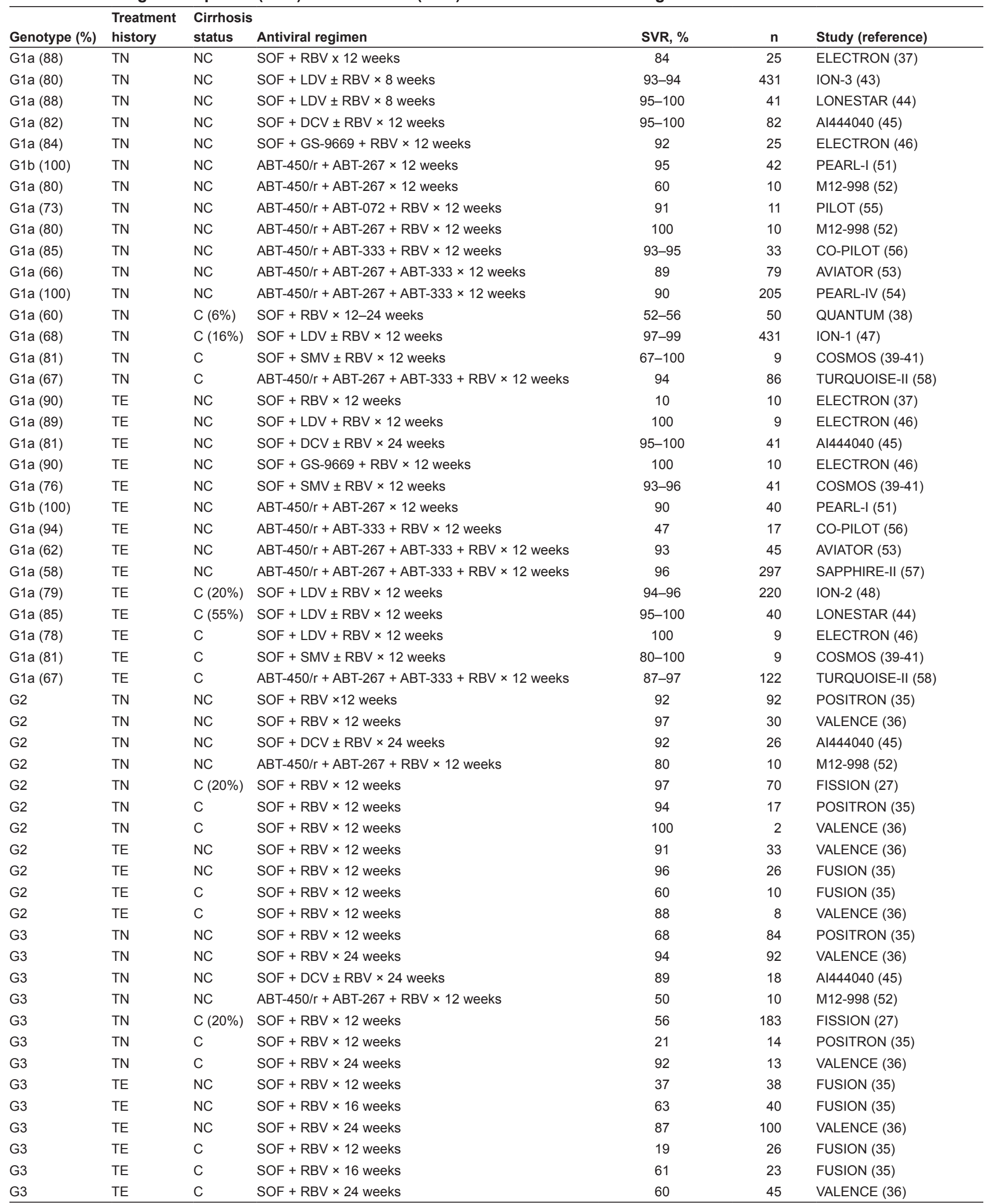

ABT-267 Ombitasvir; ABT-333 Dasabuvir; C Cirrhotic; DCV Daclatasvir; G Genotype; LDV Ledipasvir; NC Noncirrhotic; $r$ Ritonavir; RBV Ribavirin; SMV Simeprevir; TE Treatment experienced; TN Treatment naive 
$89 \%$ to $90 \%$ with the addition of dasabuvir (ABT-333) (NS5B nonnucleoside polymerase inhibitor) in AVIATOR (53), in which G1a was present in $61 \%$ to $68 \%$, and in PEARL-IV (54), in which G1a was present in $100 \%$. Similarly, ABT-450/r and RBV in combination with ABT-072 (NS5B non-nucleoside polymerase inhibitor) for 12 weeks produced a SVR of $91 \%$ in PILOT (55) in which G1a was present in $73 \%$, whereas ABT-450/r and RBV in combination with dasabuvir for 12 weeks produced a SVR of $93 \%$ to $95 \%$ in CO-PILOT (56) in which G1a was present in $79 \%$ to $90 \%$. Importantly, one patient experienced a late relapse at 36 weeks post-treatment in PILOT (55), raising the concern that longer follow-up beyond 24 weeks may be needed with IFN-free regimens. In G1 treatment-experienced noncirrhotic patients, ABT-450/r and ombitasvir given for 12 weeks resulted in an SVR of $90 \%$ in G1b in PEARL-I (51), whereas ABT-450/r, dasabuvir and RBV given for 12 weeks produced a relatively disappointing SVR of $47 \%$ in CO-PILOT (56), in which G1a was present in $94 \%$ of study patients. However, when ombitasvir was added as a third DAA, the SVR improved significantly to $93 \%$ in AVIATOR (53), in which G1a was present in $62 \%$ and to $96 \%$ in SAPPHIRE-II (57), in which G1a was present in 58\%. In G1 treatment-naive and experienced cirrhotic patients (Child-Pugh class A), ABT-450/r, ombitasvir, dasabuvir and RBV given for 12 weeks produced an SVR of $94 \%$ and $87 \%$ to $97 \%$, respectively, in TURQUOISE-II (58). Finally, the M12-998 study (52) showed that 12 weeks of ABT-450, ombitasvir and RBV produced an SVR of $80 \%$ in G2 but only $50 \%$ in G3 treatment-naive noncirrhotic patients. In summary, an SVR $>90 \%$ was demonstrated in G1b noncirrhotics regardless of treatment history with ABT-450/r and ombitasvir for 12 weeks; in G1a treatment-naive noncirrhotics with ABT-450/r combined with either another DAA and RBV or two other DAAs for 12 weeks; and in G1a treatment-experienced noncirrhotics and G1 cirrhotics irrespective of treatment history with ABT-450/r, ombitasvir, dasabuvir and RBV for 12 weeks. Treatment was well tolerated in all of these clinical trials.

Other treatment regimens that included three DAAs (NS3/4A protease inhibitor, NS5A replication complex inhibitor and NS5B non-nucleoside polymerase inhibitor) also appeared to improve SVR. Asunaprevir (NS3/4A protease inhibitor) in combination with DCV (NS5A replication complex inhibitor) for 24 weeks in G1 previous null responder noncirrhotic patients produced an SVR of $65 \%$ to $100 \%$ in G1b (59-61) but only 36\% in a patient population in which G1a was present in $82 \%(34)$. The SVR remained suboptimal (23\%) with the addition of RBV (61). However, ASV, DCV and BMS791325 (NS5B non-nucleoside polymerase inhibitor) given for 12 to 24 weeks in G1 treatment-naive noncirrhotic patients resulted in a SVR of $89 \%$ to $94 \%$ in NCT01455090 (62), in which G1a was present in $72 \%$ to $75 \%$ of patients. On the other hand, unexpectedly disappointing results have been recently published involving G1 treatment-naive noncirrhotics whereby vedroprevir (VDV) (NS3/4A protease inhibitor), LDV (NS5A replication complex inhibitor), tegobuvir (NS5B non-nucleoside polymerase inhibitor) and RBV for

\section{REFERENCES}

1. World Health Organization (WHO). Viral Hepatitis - Resolutions from the 63rd World Health Assembly, 2010.

2. Remis R. Modeling the incidence and prevalence of hepatitis C infection and its sequelae in Canada, 2007 final report. Public Health Agency of Canada. 2007.

3. Myers RP, Liu MF, Shaheen AAM. The burden of hepatitis $C$ virus infection is growing: A Canadian population-based study of hospitalizations from 1994 to 2004. Can J Gastroenterol 2008;22:381-7.

4. Dungum M, O'Shea R. Hepatitis C virus: Here comes all-oral treatment. Cleve Clin J Med 2014;81:159-72.

5. Manns MP, McHutchison JG, Gordon SC, et al. Peginterferon alfa$2 \mathrm{~b}$ plus ribavirin compared with interferon alfa- $2 \mathrm{~b}$ plus ribavirin for initial treatment of chronic hepatitis C: A randomized trial. Lancet 2001;358:958-65.
12 to 24 weeks produced a surprisingly low SVR of only 54 to $63 \%$ in the QUAD trial (63) in which G1a was present in $67 \%$ to $76 \%$ of patients. Finally, MK-5172 (NS3/4A protease inhibitor), MK-8472 (NS5A replication complex inhibitor), and RBV for 12 weeks resulted in a remarkable SVR of $96 \%$ to $100 \%$ in C-WORTHY trial (64) in which G1a was present in $70 \%$ to $76 \%$ of patients.

\section{CONCLUSION}

As the present brief review indicates, there are many DAAs that have been through clinical trials, both currently and in the recent past, that seek to provide an efficacious, IFN-free treatment for the long-term clearance of HCV. Clearly not all of these agents will survive to licensure and the marketplace. It is commonly accepted that the ideal DAA combination should include such primary characteristics as potent antiviral efficacy, high genetic barrier to resistance, broad genotypic coverage, minimal side effects and favourable safety profile, whereas secondary characteristics should include low pill burden, short treatment duration, no dietary restriction, few drug interactions and affordable drug cost (10). The optimal antiviral regimen likely entails combination of an NS5B nucleotide polymerase inhibitor with either a second-generation NS3/4A protease inhibitor or a NS5A replication complex inhibitor. The role of RBV requires further clarification but appears to be unnecessary when two DAAs with potent antiviral efficacy and high genetic barrier to resistance are used. Although it is too early to declare that PEG-IFN is 'dead', clearly in the near future, its role in HCV treatment will continue to diminish. Despite the recent advances in DAA drug development, many questions remain unanswered. Whether resistance testing is warranted before treatment initiation or in virological failure to IFN-free regimens remains to be elucidated. It is also unclear whether prolonged follow-up beyond 24 weeks post-treatment is necessary with IFN-free regimens. Finally, more data from future research are needed in HCV G4, G5 and G6, and in difficult-to-cure patient populations, which include decompensated cirrhosis, renal failure, HIV coinfection, solid organ transplantation, and pre- and post-liver transplantation. The most important question of whether long-term HCV clearance will also result in clinical improvement in patients with early decompensated cirrhosis, as has been the situation in hepatitis B, remains unknown and awaits further experience with IFN-free DAAs.

DISCLOSURES: Dr Yau does not have any competing interests. Dr Yoshida has been an investigator in hepatitis $\mathrm{C}$ clinical trials sponsored by Hoffmann LaRoche, Merck Inc, Vertex Inc, Gilead Sciences Inc, Pfizer Inc, Norvartis Inc, Boehringer Ingelheim Inc, Janssen Inc and AbbVie Inc. He has participated in Advisory Board meetings of Hoffmann LaRoche Canada, Vertex Canada and Boehringer Ingelheim Canada. He has received honoraria for CME lectures provided by Vertex Canada, Gilead Canada and Merck Canada.

6. Fried MW, Shiffman ML, Reddy R, et al. Peginterferon alfa-2a plus ribavirin for chronic hepatitis $\mathrm{C}$ virus infection. $\mathrm{N}$ Engl J Med 2002;347:975-82.

7. Hézode C, Fontaine H, Dorival C, et al. Triple therapy in treatment-experienced patients with HCV-cirrhosis in a multicenter cohort of the French Early Access Programme (ANRS CO20CUPIC) - NCT01514890. J Hepatol 2013;59:434-41.

8. Ward RP, Kugelmas M. Using pegylated interferon and ribavirin to treat patients with chronic hepatitis C. Am Fam Physician 2005;72:655-62.

9. Bruchfeld A, Lindahl K, Stahle L, et al. Interferon and ribavirin treatment in patients with hepatitis $\mathrm{C}$-associated renal disease and renal insufficiency. Nephrol Dial Transplant 2003;18:1573-80.

10. Schinazi R, Halfon P, Marcellin P, Asselah T. HCV direct-acting antiviral agents: The best interferon-free combinations.

Liver Int 2014;34(S1):69-78. 
11. Kwo PY, Lawitz EJ, McCone J, et al. Efficacy of boceprevir, an NS3 protease inhibitor, in combination with peginterferon alfa-2b and ribavirin in treatment-naïve patients with genotype 1 hepatitis $\mathrm{C}$ infection (SPRINT-1): An open-label, randomized, multicenter phase 2 trial. Lancet 2010;376:705-16.

12. Poordad F, McCone J, Bacon BR, et al. Boceprevir for untreated chronic HCV genotype 1 infection. N Engl J Med 2011;364:1195-206.

13. Jacobson IM, McHutchison JG, Dusheiko G, et al. Telaprevir for previously untreated chronic hepatitis $\mathrm{C}$ virus infection. N Engl J Med 2011;364:2405-16.

14. Lange CM, Zeuzem S. Perspectives and challenges of interferon-free therapy for chronic hepatitis C. J Hepatol 2013;58:583-92.

15. Stedman CA. Current prospects for interferon-free treatment of hepatitis C in 2012. J Gastroenterol Hepatol 2013;28:38-45.

16. Bacon BR, Gordon SC, Lawitz E, et al. Boceprevir for previously treated chronic HCV genotype 1 infection. N Engl J Med 2011;364:1207-17.

17. Zeuzem S, Andreone P, Pol S, et al. Telaprevir for retreatment of HCV infection. N Engl J Med 2011;364:2417-28.

18. González-Moreno J, Payeras-Cifre A. Hepatitis C virus infection: Looking for interferon free regimens. Scientific World Journal 2013;2013(825375):1-11.

19. Jacobson IM, Dore GJ, Foster GR, et al. Simeprevir (TMC435) with peginterferon/ribavirin for chronic HCV genotype-1 infection in treatment-naïve patients: Results from QUEST-1, a phase III trial. J Hepatol 2013;58:S567-577. Abst 1425.

20. Manns M, Marcellin P, Poordad FPF, et al. Simeprevir (TMC435) with peginterferon/ribavirin for treatment of chronic HCV genotype-1 infection in treatment-naïve patients: Results from QUEST-2, a phase III trial. J Hepatol 2013;58(S567-S577): Abst 1413.

21. Fried MW, Buti M, Dore GJ, et al. Once-daily simeprevir (TMC435) with pegylated interferon and ribavirin in treatmentnaïve genotype 1 hepatitis C: The randomized PILLAR study. Hepatology 2013;58:1918-29.

22. Lawitz E, Zeuzem S, Gane E, et al. Simeprevir (TMC435) with pegylated interferon- $\alpha-2 \mathrm{a} /$ ribavirin for treatment of chronic HCV genotype 1 infection in patients who relapsed after previous interferon-based therapy: Efficacy and safety in patient subpopulations in the PROMISE phase III trial. 64th Annual Meeting of the American Association for the Study of Liver Diseases, Washington DC, November 1 to 5, 2013.

23. Zeuzem S, Berg T, Gane E, et al. Simeprevir increases rate of sustained virologic response among treatment-experienced patients with HCV genotype-1 infection: A phase IIb trial. Gastroenterology 2014;146:430-41.

24. Bae A, Sun SC, Qi X, et al. Susceptibility of treatment-naïve hepatitis $\mathrm{C}$ virus (HCV) clinical isolates to $\mathrm{HCV}$ protease inhibitors. Antimicrob Agents Chemother 2010;54:5288-97.

25. Lawitz E, Lalezari JP, Hassanein T, et al. Sofosbuvir in combination with peginterferon alfa-2a and ribavirin for non-cirrhotic, treatment-naïve patients with genotypes 1,2 , and 3 hepatitis $C$ infection: A randomized, double-blind, phase 2 trial. Lancet Infect Dis 2013;13:401-8.

26. Kowdley KV, Lawitz E, Crespo I, et al. Sofosbuvir with pegylated interferon alfa-2a and ribavirin for treatment-naïve patients with hepatitis C genotype-1 infection (ATOMIC): An open-label, randomized, multicentre phase 2 trial. Lancet 2013;381:2100-7.

27. Lawitz E, Mangia A, Wyles D, et al. Sofosbuvir for previously untreated chronic hepatitis C infection. N Engl J Med 2013;368:1878-87.

28. Lalezari J, Lawitz E, Rodriguez-Torres M, et al. Once daily PSI-7977 plus PegIFN/RBV in a phase $2 \mathrm{~b}$ trial: Rapid virologic suppression in treatment-naive patients with HCV GT2/GT3. J Hepatol 2011;54(S25-S44):Abst 61.

29. Lawitz E, Poordad F, Brainard DM, et al. Sofosbuvir in combination with PegIFN and ribavirin for 12 weeks provides high SVR rates in HCV-infected genotype 2 or 3 treatment-experienced patients with and without compensated cirrhosis: Results from the LONESTAR-2 study. 64th Annual Meeting of the American Association for the Study of Liver Diseases, Washington DC, November 1 to 5, 2013.

30. Younossi ZM, Stepanova M, Henry L, et al. Minimal impact of sofosbuvir and ribavirin on health related quality of life in chronic hepatitis C (CH-C). J Hepatol 2014;60:741-7.

31. Younossi ZM, Stepanova M, Henry L, et al. Effects of sofosbuvirbased treatment, with and without interferon, on outcome and productivity of patients with chronic hepatitis C. Clin Gastroenterol Hepatol 2013;S1542-3565(13)01838-7.

32. Younossi ZM, Singer ME, Mir HM, et al. Impact of interferon free regimens on clinical and cost outcomes for chronic hepatitis $\mathrm{C}$ genotype 1 patients. J Hepatol 2014;60:530-7.

33. Gane EJ, Roberts SK, Stedman CA, et al. Oral combination therapy with a nucleoside polymerase inhibitor (RG7128) and danoprevir for chronic hepatitis $\mathrm{C}$ genotype 1 infection (INFORM-1): A randomized, double-blind, placebo-controlled, dose-escalation trial. Lancet 2010;376:1467-75.

34. Lok AS, Gardiner AF, Lawitz E, et al. Preliminary study of two antiviral agents for hepatitis $\mathrm{C}$ genotype 1 . N Engl J Med 2012;366:216-24.

35. Jacobson IM, Gordon SC, Kowdley KV, et al. Sofosbuvir for hepatitis $\mathrm{C}$ genotype 2 or 3 in patients without treatment options. N Engl J Med 2013;368:1867-77.

36. Zeuzem S, Dusheiko GM, Salupere R, et al. Sofosbuvir + ribavirin for 12 or 24 weeks for patients with HCV genotype 2 or 3: The VALENCE trial. 64th Annual Meeting of the American Association for the Study of Liver Diseases, Washington DC, November 1 to 5, 2013.

37. Gane EJ, Stedman CA, Hyland RH, et al. Nucleotide polymerase inhibitor sofosbuvir plus ribavirin for hepatitis C. N Engl J Med 2013;368:34-44.

38. Lalezari JP, Nelson DR, Hyland RH, et al. Once-daily sofosbuvir plus ribavirin given for 12 or 24 weeks in treatment-naive patients with HCV infection: The QUANTUM study. J Hepatol 2013;58:S229-407.

39. Jacobson IM, Ghalib RH, Rodriguez-Torres M, et al. SVR results of a once-daily regimen of simeprevir (TMV435) plus sofosbuvir (GS-7977) with or without ribavirin in cirrhotic and non-cirrhotic HCV genotype 1 treatment-naïve and prior null responder patients: The COSMOS study. 64th Annual Meeting of the American Association for the Study of Liver Diseases, Washington DC, November 1 to 5, 2013. Abst LB-3.

40. Sulkowski M, Jacobson IM, Ghalib R, et al. Once-daily simeprevir (TMC435) plus sofosbuvir (GS-7977) with or without ribavirin in HCV genotype 1 prior null responders with metavir FO-2: COSMOS study subgroup analysis. J Hepatol 2014;60:S4. A7 (Abst).

41. Lawitz E, Ghalib R, Rodriguez-Torres M, et al. Simeprevir plus sofosbuvir with/without ribavirin in HCV genotype 1 prior nullresponder/treatment-naïve patients (COSMOS study). Primary endpoint (SVR12) results in patients with metavir F3-4 (Cohort 2). J Hepatol 2014;60(1):S524:A165 (Abst).

42. Sharma P, Lok AS. Interferon-free treatment regimens for hepatitis $C$ : Are we there yet? Gastroenterology 2011;141:1963-7.

43. Kowdley KV, Gordon SC, Reddy KR, et al. Ledipasvir and sofosbuvir for 8 or 12 weeks for chronic HCV without cirrhosis. N Engl J Med 2014;370:1879-88.

44. Lawitz E, Poordad FF, Pang PS, et al. Sofosbuvir and ledipasvir fixed-dose combination with and without ribavirin in treatmentnaïve and previously treated patients with genotype 1 hepatitis $\mathrm{C}$ virus infection (LONESTAR): An open-label, randomized, phase 2 trial. Lancet 2014;383:515-23.

45. Sulkowski MS, Gardiner DF, Rodriguez-Torres M, et al. Daclatasvir plus sofosbuvir for previously treated or untreated chronic HCV infection. N Engl J Med 2014;370:211-21.

46. Gane EJ, Stedman CA, Hyland RH, et al. Efficacy of nucleotide polymerase inhibitor sofosbuvir plus the NS5A inhibitor ledipasvir or the NS5B non-nucleoside inhibitor GS-9669 against HCV genotype 1 infection. Gastroenteroloy 2014;146:736-43.

47. Afdhal N, Zeuzem S, Kwo P, et al. Ledipasvir and sofosbuvir for untreated HCV genotype 1 infection. N Engl J Med 2014;370:1889-98.

48. Afdhal N, Reddy R, Nelson DR, et al. Ledipasvir and sofosbuvir for previously treated HCV genotype 1 infection. N Engl J Med 2014;370:1483-93.

49. Gane EJ, Pockros P, Zeuzem S, et al. Interferon-free treatment with a combination of mericitabine and danoprevir with or without ribavirin in treatment-naïve HCV genotype 1-infected patients. J Hepatol 2012;56:S555-6.

50. Feld JJ, Jacobson IM, Jensen DM, et al. Up to 100\% SVR4 rates with ritonavir-boosted danoprevir $(\mathrm{DNVr})$, mericitabine (MCB) and ribavirin $(\mathrm{R})+/$ - peginterferon alfa-2a $(40 \mathrm{KD})(\mathrm{P})$ in $\mathrm{HCV}$ genotype 1 -infected partial and null responders: results from the MATTERHORN study. Hepatology 2012;56(S4):231A-232A. 
51. Lawitz E, Hezode $\mathrm{C}$, Varunok $\mathrm{P}$, et al. Interferon- and ribavirin-free regimen of ABT-450/r + ABT-267 in HCV genotype 1b-infected treatment-naïve patients and prior null responders (Abstr 75). 64th Annual Meeting of the American Association for the Study of Liver Diseases, Washington, DC, November 1 to 5, 2013. (Abst)

52. Lawitz E, Sullivan G, Rodriguez-Torres M, et al. A 12-week trial of interferon-free regimens containing ABT-450/r and ABT-267 +/ribavirin (RBV) in treatment-naïve patients with HCV genotypes 1-3. Hepatol Int 2013;7(S1):S358-9.

53. Kowdley KV, Lawitz E, Poordad F, et al. Phase $2 \mathrm{~b}$ trial of interferonfree therapy for hepatitis $\mathrm{C}$ virus genotype 1 . N Engl J Med 2014;370:222-32.

54. Ferenci P, Bernstein D, Lalezari J, et al. ABT-450/r-ombitasvir and dasabuvir with or without ribavirin for HCV. N Engl J Med 2014;370:1983-92.

55. Lawitz E, Poordad F, Kowdley KV, et al. A phase 2a trial of 12-week interferon-free therapy with two direct-acting antivirals (ABT-450/r, ABT-072) and ribavirin in IL28B C/C patients with chronic hepatitis C genotype 1. J Hepatol 2013;59:18-23.

56. Poordad F, Lawitz E, Kowdley KV, et al. Exploratory study of oral combination antiviral therapy for hepatitis C. N Engl J Med 2013;368:45-53.

57. Zeuzem S, Jacobson IM, Baykal T, et al. Retreatment of HCV with ABT-450/r-ombitasvir and dasabuvir with ribavirin. N Engl J Med 2014;370:1604-14.

58. Poordad F, Hezode C, Trinh R, et al. ABT-450/r-ombitasvir and dasabuvir with ribavirin for hepatitis $\mathrm{C}$ with cirrhosis. N Engl J Med 2014;370:1973-82.
59. Chayama K, Takahashi S, Toyota J, et al. Dual therapy with the nonstructural protein $5 \mathrm{~A}$ inhibitor, daclatasvir, and the nonstructural protein 3 protease inhibitor, asunaprevir, in hepatitis $\mathrm{C}$ virus genotype $1 \mathrm{~b}$-infected null responders. Hepatology 2012;55:742-8

60. Suzuki Y, Ikeda K, Suzuki F, et al. Dual oral therapy with daclatasvir and asunaprevir for patients with HCV genotype $1 \mathrm{~b}$ infection and limited treatment options. J Hepatol 2013;58:655-62.

61. Lok AS, Gardiner DF, Hezode C, et al. Randomized trial of daclatasvir and asunaprevir with or without PegIFN/RBV for hepatitis $\mathrm{C}$ virus genotype 1 null responders. J Hepatol 2014;60:490-9.

62. Everson GT, Sims KD, Rodriguez-Torres M, et al. Efficacy of an interferon- and ribavirin-free regimen of daclatasvir, asunaprevir, and BMS-791325 in treatment-naïve patients with HCV genotype 1 infection. Gastroenterology 2014;146:420-9.

63. Wyles DL, Rodriguez-Torres M, Lawitz E, et al. All-oral combination of ledipasvir, vedroprevir, tegobuvir, and ribavirin in treatment-naïve patients with genotype $1 \mathrm{HCV}$ infection. Hepatology 2014 (Epub ahead of print).

64. Lawitz E, Vierling J, Murillo A, et al. High efficacy and safety of the all-oral combination regimen, MK-5172/MK-8742 +/- RBV for 12 weeks in HCV genotype 1 infected patients: The C-WORTHY study. 64th Annual Meeting of the American Association for the Study of Liver Diseases, Washington, DC, November 1 to 5, 2013. 


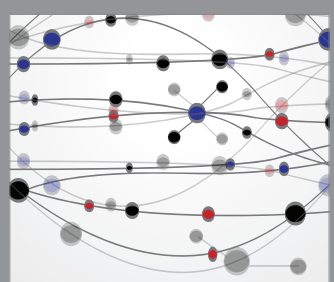

The Scientific World Journal
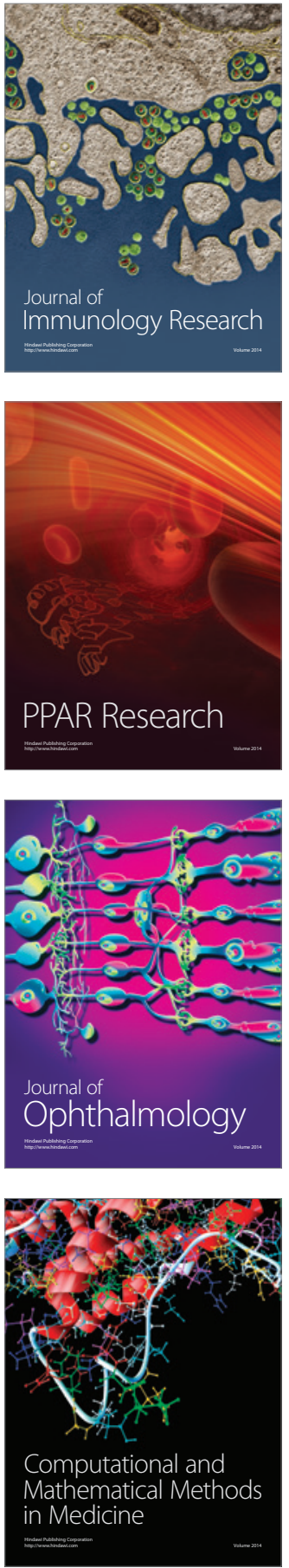

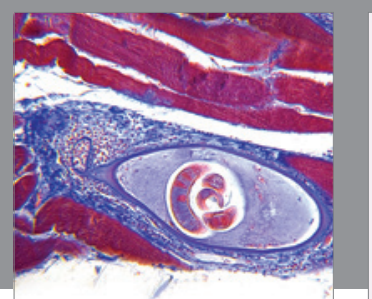

Gastroenterology Research and Practice

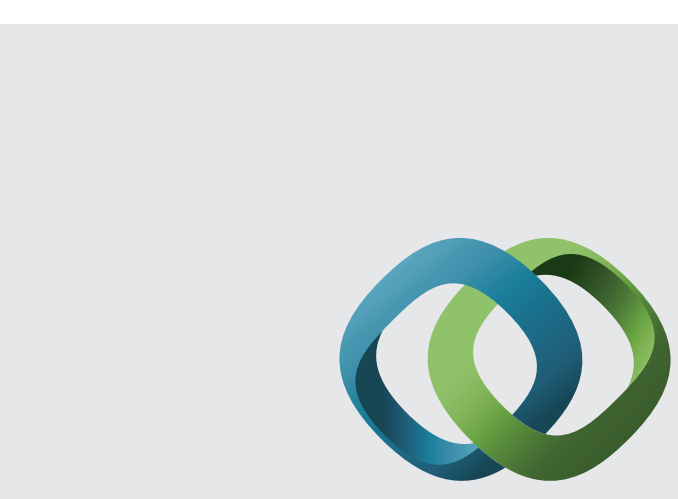

\section{Hindawi}

Submit your manuscripts at

http://www.hindawi.com
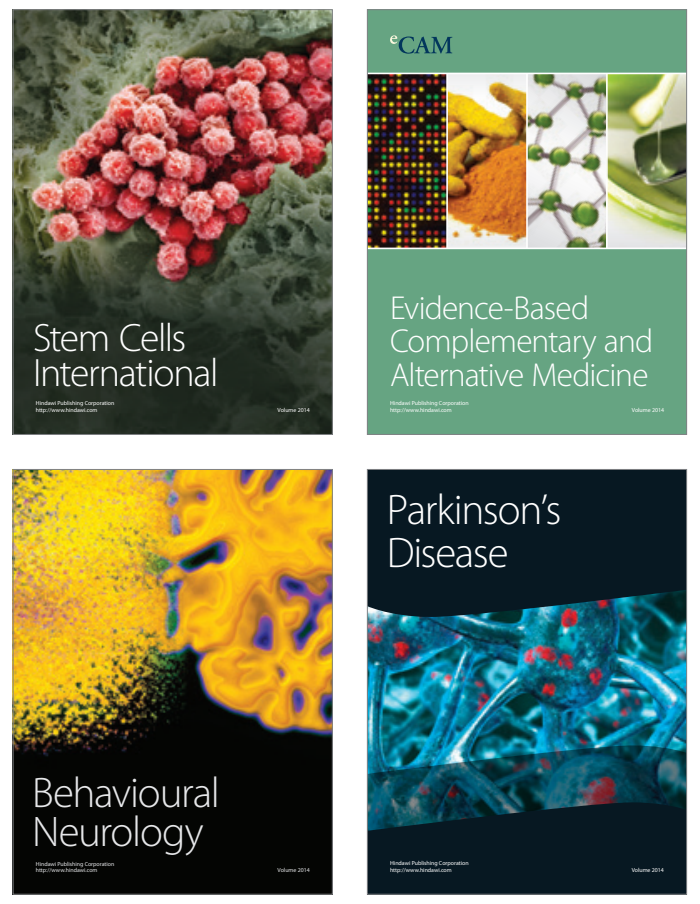
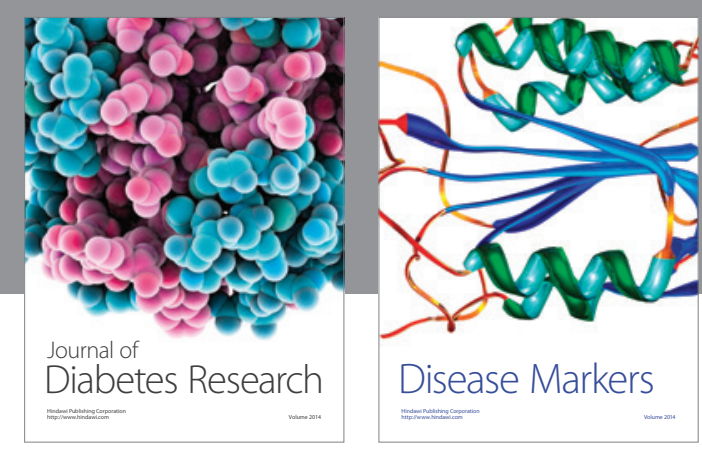

Disease Markers
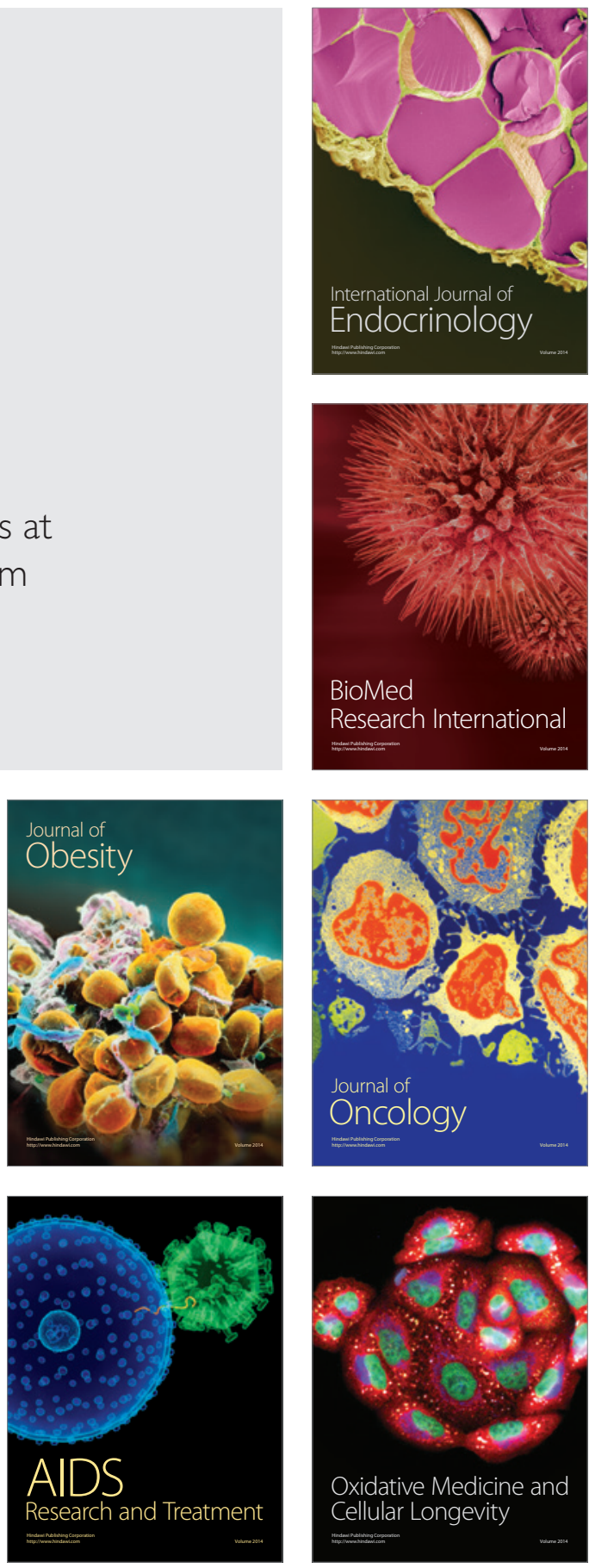